\title{
UTICAJ PLIOMETRIJSKOG TRENINGA NA EKSPLOZIVNU SNAGU OPRUŽAČA NOGU
}

\author{
Aleksandar Kukrić ${ }^{1}$, Borko Petrović ${ }^{1}$, Radenko Dobraš ${ }^{1}$ i Bojan Guzina ${ }^{1}$ \\ ${ }^{1}$ Fakultet fizičkog vaspitanja i sporta, Banja Luka, BiH
}

DOI: $10.5550 /$ sgia. 100114

COBISS.BH-ID 1844504

Orginalni naučni članak UDK: $796.015=163$

\section{SUMMARY}

In the period of ten weeks junior basketball players divided into two experimental and control groups, were subjected to various training programs. Patients in experimental group, in addition to regular basketball training, additional trained plyometric model of training twice a week, while respondents in the control group had only a technical-tactical basketball training. The aim of this study was to test the impact of content plyometric training on explosive leg strength exstensors in performing various jumps in junior basketball players. Tested were two jumps: Countermovement jump and Squat jump, and observed the following variables: maximum jump height (h), maximum force in concentric contraction $\left(F_{\max }\right)$ and time implementation maximum force in concentric contraction $\left(t_{\max }\right)$. Comparing the results obtained on the basis of initial and final measurements unambiguously proved that the tested variables are changed under the influence of experimental factors. In two tested jump significantly improve the maximum jump height $(p=.00)$ and maximum force $(p=.00)$. Time implementation maximum force is not changed significantly during the ten weeks treatment. Research has proven that plyometric training methods affect the development of explosive strength of legs extensors of basketball junior players.

Key words: stertch-shortening cycles, vertical jump, force, basketball player

\section{UVOD}

Pliometrijski trening je možda jedan od najzanimljivijih trenažnih inovacija u posljednjih pedeset godina. I ova metoda se u početku smatrala tajnom kojom su Rusi dominirali u atletici i drugim sportovima. Međutim, pliometrija se pojavila mnogo ranije, još tridesetih godina prošlog vijeka. $U$ istočnoj i sjevernoj Evropi koristili su se treninzi skokova, a tek uspjeh Ruskih skakača u vis i troskokaša šezdesetih godina prošlog vijeka potaknulo je razmišljanje o pliometriji. Teorija o dominantnoj ulozi korišćenja elastične energije mišića prvi put se pojavila šezdesetih godina u djelima Zaciorskog, a dokazana je kroz niz kasnijih radova (Bosco i sar, 1982; Adams i sar, 1992; Holcomb, 1996; Potteiger, 1999; Komi, 2000. I unazad deset godina, pliometrijski trening je bio aktuelna tema istraživanja (Fatouros i sar, 2000;
Matavulj, 2001; Luebbers, 2003; Kotzamanidis, 2006; Potach, 2009), koja su potvrdila njegovu efikasnost u trenažnim programima.

$U$ osnovi pliometrijskog modela treninga je ciklus skraćenje-istezanje ili Stretch-Shortening Cycle-SSC. Stimulišući mišić određenom silom (opterećenjem) prouzrokovaćemo njegovu reakciju. Ta reakcija biće deformacija u njegovoj dimenziji koju nazivamo istezanjem. Ovakvom deformacijom prouzrokovaćemo akumuliranje energije elestične deformacije, čiji se najveći dio skladišti u mišićnim tetivama. Time se stvara veća mišićna tenzija što će prouzrokaovati $i$ veću mišićnu silu. Akumulirana energija zavisi od dužine tetiva i njihove krutosti, indirektno od njihove debljine (Matavulj, 2001). Pošto se energija akumulira i u mišićnim ovojnicama zaključujemo da količina energije elastične deformacije zavisi od "količine" vezivnog tkiva mišića. Brzo istezanje mišića aktivira refleks 
mišićnog vretena koji šalje jak nervni impuls preko leđne moždine natrag u mišić koji potom reaguje skraćenjem. Ovo nazivamo refleks istezanja ili miotatički refleks. Većina autora (Bosco, 1982; Komi, 2000; Kyrolainen, 2005) smatra da je potreban što brži prelaz između ekscentrične i koncentrične kontrakcije kako bi se ta energija iskoristila. Vrijeme transfera iz ekscentrične faze u koncentričnu fazu ne smije biti duže od životne dobi povezanih poprečnih mostova. Ako je taj transfer predug, poprečni mostovi se rasklapaju i elastična energija koja je bila skladištena u tim jedinicama ne može se više upotrebiti za koncentričnu kontrakciju, te se ukupni učinak ekscentrično-koncentrične kontrakcije umanjuje za 20-30\%.

Rukovodeći se prethodno navedenim, cilj ovog rada je bio da se utvrdi na koji način sadržaji pliometrijskog modela treninga utiču na maksimalnu visinu skoka, kao i vrijednosti maksi-malne sile $i$ vremena njenog ostvarenja u kon-centričnoj kontrakciji prilikom izvođenja različitih skokova kod košarkaša juniora.

\section{METODE}

\section{Uzorak ispitanika}

Uzorak ispitanika čine dvadeset košarkaša juniora, članovi KK "Igokea" Aleksandrovac i KK "Alfom" Banja Luka. Ispitanici su normalnog zdravstvenog statusa, podijeljeni u dvije grupe: eksperimentalnu (Eksp.) i kontrolnu (Kont.). U trenutku testiranja svi ispitanici su bili zdravi i bez povreda donjih ekstremiteta. Grupe su nakon inicijalnog mjerenja homogenizovane na osnovu Z-vrijednosti svake kriterijumske varijable, kao preduslov primjene eksperimenta s paralelnim grupama.

\section{Uzorak varijabli}

Testirana su dvije varijante vertikalnog skoka:

1. Countermovement jump - sunožan skok iz mjesta sa rukama na kukovima, $i$

2. Squat jump - sunožan skok iz polučučnja sa rukama na kukovima.

U okviru svakog skoka testirane su sljedeće varijable:

1. Maksimalna visina skoka $(H)$,
2. Maksimalna sila u koncentričnoj kontrakciji $\left(F_{\text {max }}\right), i$

3. Vrijeme ostvarenja maksimalne sile $u$ koncentričnoj kontrakciji $\left(t_{\max }\right)$.

Nakon zagrijavanja, svaki ispitanik je izveo dva različita vertikalna skoka na platformi sile: Countermovement jump kod kojeg se ispitanik iz normalnog uspravnog stava spusti u položaj polučučanja i bez zadržavanja maksimalno skoči i Squat jump kod kojeg se ispitanik zauzme poziciju polučučnja, te nakon toga izvede skok. Svaki skok se izvodio u tri pokušaja, pri čemu su najbolji skokovi izabrani za dalje analize. Pauza između testiranih skokova trajala je pet minuta.

\section{Tok i postupci istraživanja}

$U$ periodu od deset sedmica eksperimentalna grupa je pored redovnih košarkaških treninga dodatno trenirala pliometrijskim trenažnim modelom dva puta sedmično, dok je kontrolna grupa imala samo tehničko-taktičke košarkaške treninge. Program pliometriskog treninga korištenog u ovom istraživanju sastojao se od različitih skokova u mjestu i u kretanju, skokova u dubinu, poskoka, skokova na sanduk... Tokom prve sedmice programa izvodile su se 5 različitih vježbi u dvije serije sa 10 ponavljanja u okviru svake serije, tako da je prosječno ostvareno 100 kontakata sa tlom. Sadržaj treninga su bile različite varijante skokova. Na početku programa dominirale su jednostavnije vježbe, a kako su ispitanici napredovali $i$ vježbe su bile sve složenije i prilagođene trenutnim sposobnostima ispitanika. U petoj sedmici programa izvodili su se sve složeniji skokovi kroz 7 različitih vježbi, u dvije serije sa 10 ponavljanja u okviru serije, tako da je broj kontakata sa tlom iznosio u prosjeku 140. U desetoj sedmici izvodili su se najsloženiji skokovi (dominirali su skokovi u dubinu), a organizovani su kroz 8 različitih vježbi u dvije serije i 10 ponavljanja. Pauza između serija je bila 3 minuta, a između vježbi 5 minuta.

Ispitanici su testirani u laboratorijskim uslovima, uz pomoć TANITE BC-418MA, (tjelesna masa), antropometra po Martinu (tjelesna visina) $i$ GLOBUS ERGO TESYS SYSTEM 1000", standardnom procedurom na platformama sile (Countermovement jump i Squat jump). Prije samog testiranja izvršen je praktičan prikaz testiranih 
skokova, te je omogućena probna serija skokova.

\section{Statistička obrada podataka}

Podaci dobijeni istraživanjem obrađeni su pri-mjenom deskriptivne i komparativne statističke analize primjenom operativnog sistema SPSS 14.0.

U okviru deskriptivne statistike za sve varijable određene su: aritmetička sredina $i$ standardna devijacija.

U okviru komparativne statistike primjenjen je Studentov t-test za procjenu razlika između tetstiranih grupa na inicijalnom i finalnom mjere-nju. Kao nivo statističke značajnosti određeno je da je $p<0.05$.

\section{REZULTATI}

U tabelama 1 i 2 prikazani su osnovni deskriptivni parametri testiranih varijabli na inicijalnom i finalnom mjerenju za eksperimentalnu i kontrolnu grupu. Uočavamo da je na inicijalnom mjerenju varijabilitet rezultata bio sličan u svim testiranim varijablama obe grupe, dok na finalnom mjerenju to nije slučaj.

U slikama 1, 2 i 3 predstavljena je značajnost razlika aritmetičkih sredina testiranih varijabli eksperimentalne $i$ kontrolne grupe na inicijalnom i finalnom mjerenju u testu Countermovment jump. Analizirajući vrijednosti uočavamo da je u eksperimentalnoj grupi došlo do statistički značajnog povećanja maksimalne visine skoka $(p=.00)$ i maksimalne sile $(p=.00)$, dok je vrijeme za koje je maksimalna sila ostvarena ostalo nepromenjeno $(p=.52)$. $U$ kontrolnoj grupi nije bilo značajnijih promjena.

\section{SLIKA 1.}

Značajnost razlika aritmetičkih sredina maksimalne visine skoka $(\mathrm{cm})$ ispitanika eksperimentalne $i$ kontrolne grupe u inicijalnom i finalnom mjerenju u testu Countermovement jump.

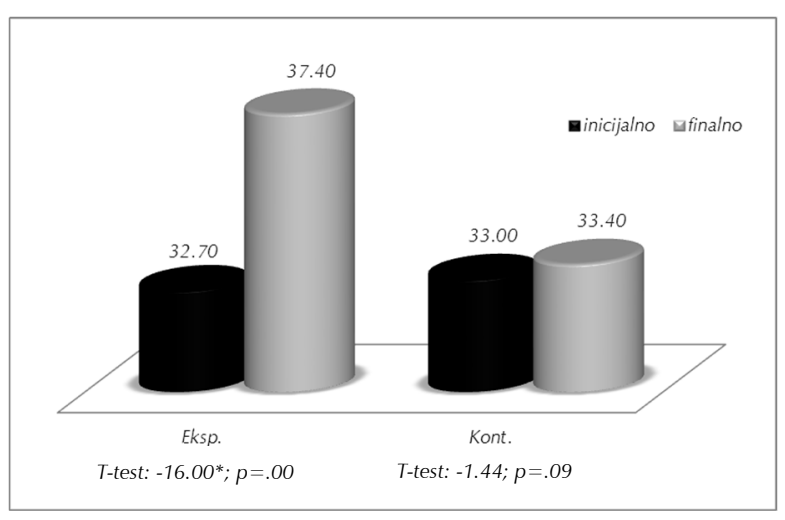

\section{TABELA 1.}

Aritmetička sredina i standardno odstupanje rezultata eksperimentalne i kontrolne grupe na inicijalnom mjerenju.

\begin{tabular}{ccccccccc}
\hline & \multicolumn{4}{c}{ Countermovement jump } & \multicolumn{3}{c}{ Squat jump } \\
\cline { 2 - 10 } & \multicolumn{3}{c}{ AS } & \multicolumn{3}{c}{ SD } & \multicolumn{3}{c}{ AS } \\
\cline { 2 - 10 } & Eks. & Kon. & Eks. & Kon. & Eks. & Kon. & Eks. & Kon. \\
\hline$H(\mathrm{~cm})$ & 32.70 & 33.00 & 2.58 & 2.40 & 31.20 & 30.70 & 1.81 & 2.98 \\
\hline Fmax $(\mathrm{N})$ & 1683.16 & 1671.50 & 148.60 & 149.24 & 1656.70 & 1753.75 & 99.97 & 82.74 \\
\hline$t \max (\mathrm{s})$ & .190 & .191 & .03 & .02 & .180 & .181 & .05 & .03 \\
\hline
\end{tabular}

Legenda: AS - aritmetička sredina, SD - standardna devijacija, Eks. - eksperimentalna, Kon. - kontrolna

\section{TABELA 2.}

Aritmetička sredina i standardno odstupanje rezultata eksperimentalne i kontrolne grupe na finalnom mjerenju.

\begin{tabular}{ccccccccc}
\hline & \multicolumn{4}{c}{ Countermovement jump } & \multicolumn{3}{c}{ Squat jump } \\
\cline { 2 - 9 } & \multicolumn{3}{c}{ AS } & \multicolumn{3}{c}{ SD } & & \multicolumn{2}{c}{ SD } \\
\cline { 2 - 9 } & Eks. & Kon. & Eks. & Kon. & Eks. & Kon. & Eks. & Kon. \\
\hline$H(\mathrm{~cm})$ & 37.40 & 33.40 & 2.79 & 2.27 & 36.00 & 31.10 & 2.25 & 2.80 \\
\hline Fmax $(\mathrm{N})$ & 1931.27 & 1695.29 & 45.65 & 140.68 & 1905.47 & 1782.50 & 114.25 & 76.00 \\
\hline$t \max (\mathrm{s})$ & .189 & .192 & .02 & .03 & .181 & .179 & .04 & .02 \\
\hline
\end{tabular}

Legenda: AS - aritmetička sredina, SD - standardna devijacija, Eks. - eksperimentalna, Kon. - kontrolna 
SLIKA 2.

Značajnost razlika aritmetičkih sredina maksimalne sile $(\mathrm{N})$ ispitanika eksperimentalne $i$ kontrolne grupe $u$ inicijalnom i finalnom mjerenju u testu Countermovement jump.

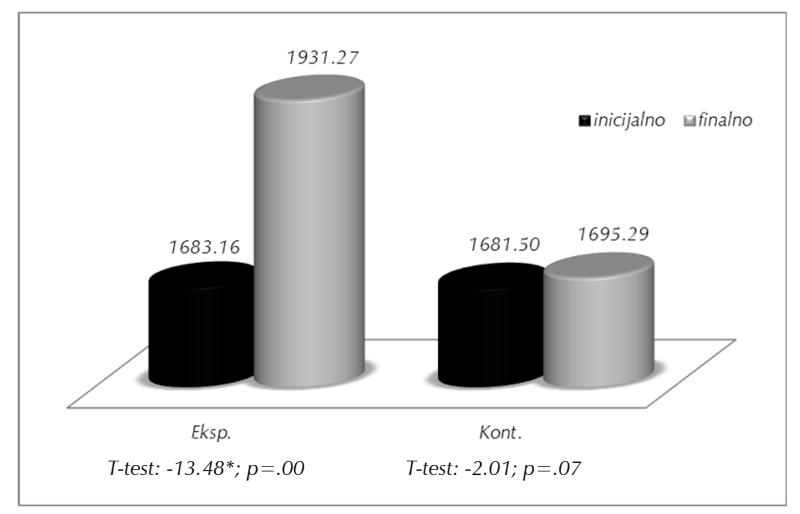

\section{SLIKA 3.}

Značajnost razlika aritmetičkih sredina vremena ostvarenja maksimalne sile (s) ispitanika eksperimentalne $i$ kontrolne grupe $u$ inicijalnom i finalnom mjerenju u testu Countermovement jump.

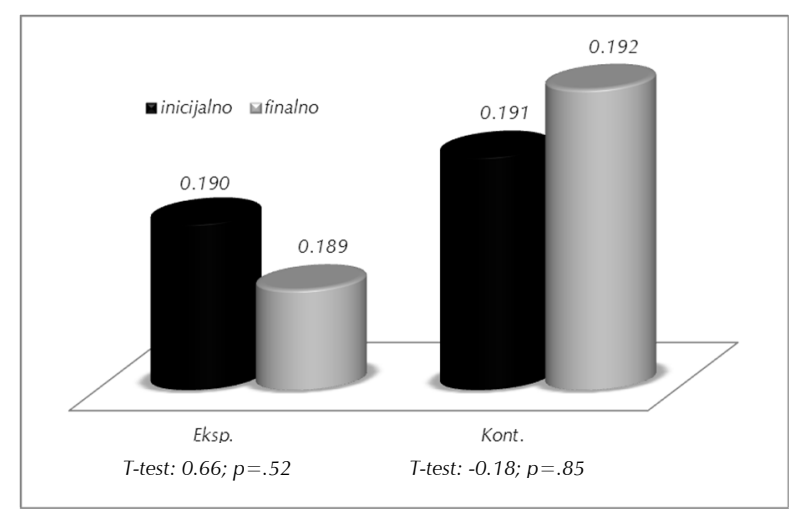

\section{SLIKA 4.}

Značajnost razlika aritmetičkih sredina maksimalne visine skoka $(\mathrm{cm})$ ispitanika eksperimentalne $i$ kontrolne grupe $u$ inicijalnom i finalnom mjerenju u testu Squat jump.

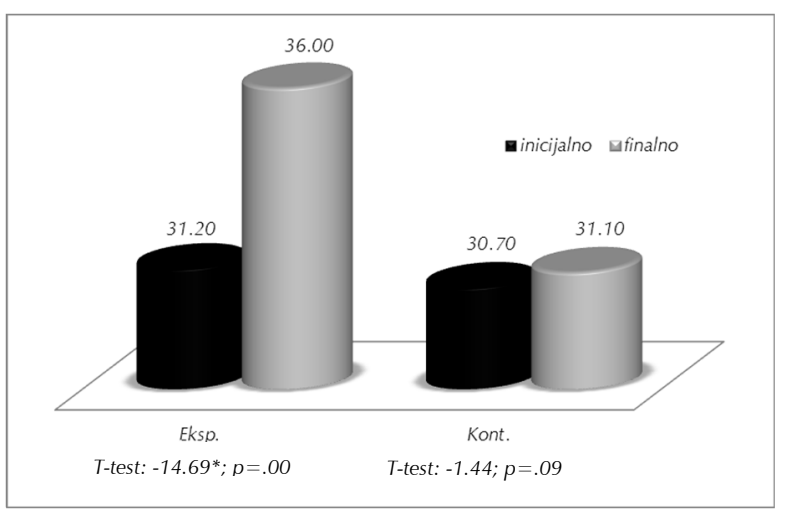

\section{SLIKA 5.}

Značajnost razlika aritmetičkih sredina maksimalne sile $(\mathrm{N})$ ispitanika eksperimentalne $i$ kontrolne grupe u inicijalnom i finalnom mjerenju u testu Squat jump.

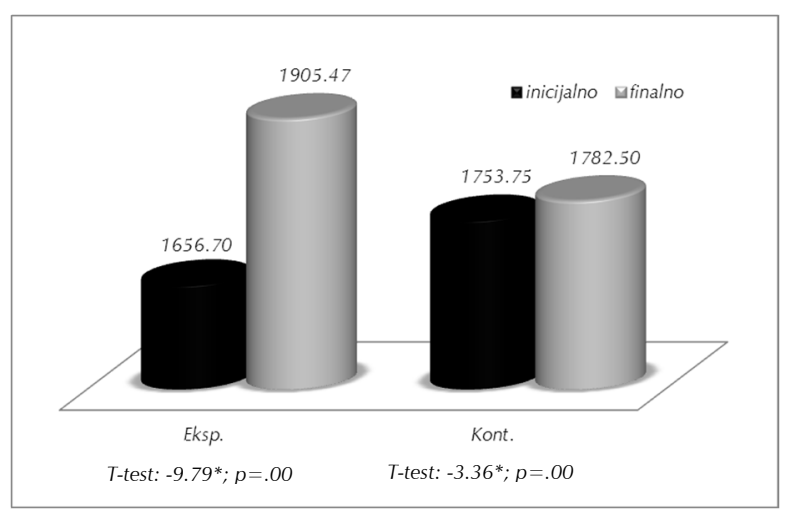

\section{SLIKA 6.}

Značajnost razlika aritmetičkih sredina vremena ostvarenja maksimalne sile (s) ispitanika eksperimentalne $i$ kontrolne grupe $u$ inicijalnom i finalnom mjerenju u testu Squat jump.

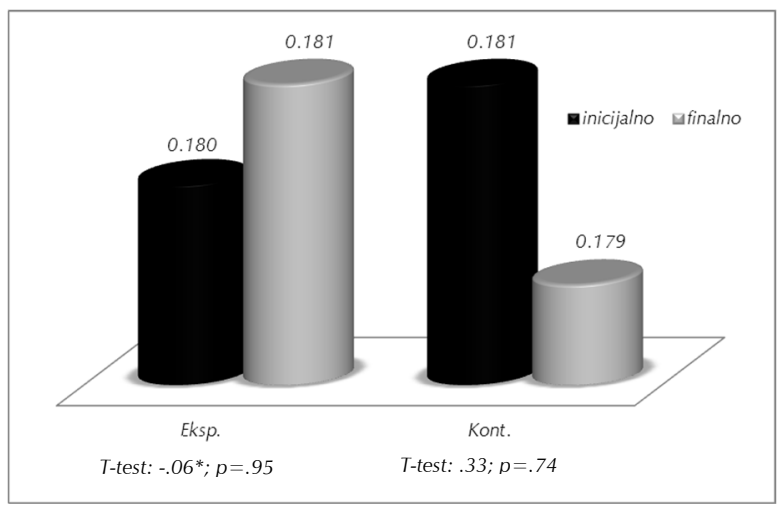

Kao i u prethodnom testu i u Squat jump-u, usljed primjene eksperimentalnog faktora, statistički značajno se poboljšala maksimalna visina skoka u eksperimentalnoj grupi $(p=.00)$, dok je to povećanje izostalo u kontrolnoj grupi $(p=.09)$ (slika 4.). Interesantne su promjene koje su se desile u varijabli maksimalna sila. Što se tiče vremena ostvarenja maksimalne sile (slika 6.), statistički značajnih promjena nije bilo u testiranim grupama.

\section{DISKUSIJA}

Upoređivanjem prosječnih vrijednosti morfoloških karakteristika ispitanika dobijenih na inicijalnom i finalnom mjerenju vidimo da se radi o 
skoro identičnim podacima (tabela 1. i 2.). Budući da su u eksperimentalnoj grupi, u dodatnim treninzima, dominirale fizičke aktivnosti submaksimalnog i maksimalnog intenziteta s kratkim periodima naprezanja, nedovoljnim da se angažuju aerobni mehanizmi, sasvim je razumljiv izostanak promjena u pogledu tjelesne mase, što bi moglo uticati na relativnu sila i na taj način indirektno poboljšati testirane parametre.

Osnovni deskriptivni parametri analiziranih varijabli skočnosti za eksperimentalnu i kontroInu grupu prikazani su u tablama 1. i 2. Uočavamo da je na inicijalnom mjerenju varijabilitet rezultata bio sličan u svim testiranim varijablama obe testirane grupe. Vrijednosti AS visine skoka na inicijalnom mjerenju je bila skoro identična u eksperimentalnoj i kontrolnoj grupi, kao i vrijednosti SD. Kad su upitanju ostale dvije testirane varijable vidimo da je varijabilitet rezultata bio približno isti u obe testirane grupe. Rezultati upućuju na izjednačenost grupa na inicijalnom mjerenju, što je i preduslov za eksperiment sa parelnim grupama. Međutim, na finalnom mjere-nju imamo putpuno drugačije vrijednosti. Primjenom eksperimentalnog tretmana promjenile su se vrijednosti maksimalne visine skoka i maksimalne sile ostvarene $u$ fazi koncentrične kontrakcije skoka, što je vidljivo iz tabele 2. Vrije-dnosti AS i SD eksperimentalne i kontrolne grupe se razlikuju, a daljim statističkim procedurama analiziraćemo da li su te promjene statistički značajne.

Analizirajući prosječne vrijednosti u testu Countermovement jump utvrdjenih na osnovu inicijalnih i finalnih mjerenja uočavamo da je u eksperimentalnoj grupi došlo do statistički značajnog povećanja maksimalne visine skoka $(p=.00)$ i maksimalne sile $(p=.00)$, dok je vrijeme za koje je maksimalna sila ostvarena ostalo nepromenjeno $(p=.52)$. Istovremeno, u kontrolnoj grupi nije došlo do značajnijih promjena ni u jednoj testiranoj varijabli (slike 1, 2 i 3).

Kao što je bilo i očekivano, pod uticajem eksperimentalnog faktora došlo je do statistički značajnog poboljšanja maksimalne visine skoka u eksperimentalnoj grupi, dok u kontrolnoj grupi nisu zabilježena poboljšanja visine skoka (slika 1.). Posljedica povećanja vrijednosti maksimalne sile, bolja intramuskularna $i$ intermuskularna koordinacija mišića omogućile su i veće vrijedno-sti vertikalnog skoka. Statistički značajno pobo-ljšanje vrijednosti maksimalne sile (slika 2.) rezu-Itat je djelimične hipertrofije mišićnih vlakana, većeg broja aktiviranih motornih jedinica, brže frekvencije pražnjenja, odnosno promjene uče-stalosti aktiviranja motornih jedinica, kao i sinhronizovanijeg rada motornih jedinica. Slične podatke dobio je $i$ Fatours i sar. (2000) upore-đujući pliometrijski metod treninga sa još dva metoda treninga $u$ periodu od deset sedmica dobili su statistički značajno povećanje maksi-malnog vertikalnog skoka i mišićne sile mišića donjih ekstremiteta.

Na stepen ispoljavanja maksimalne sile kao i brzinu njenog ispoljavnja, utiču dva faktora: periferni (sposobnost pojedinačnog mišića da razvije maksimalnu silu) i centralni (koordinacija mišićne aktivnosti koju izvodi CNS). Najvažniji periferni faktor za postizanje maksimalne mišićne sile je veličina mišića koja je direktno vezana sa površinom poprečnog presjeka. Centralni ner-vni sistem je najvažniji faktor za razvoj mišićne sile $i$ to ne samo po količini uključene mišićne mase već i po stepenu do kojeg se pojedinačna vlakna u mišiću aktiviraju (intramuskularna koordinacija mišića). Za ispoljavanje maksimalne sile mora biti uključen veći broj mišića i to na odgovarajući način. To koordinisano povezivanje više mišića predstavlja intermuskularnu koordi-naciju. Centralni nervni sistem aktiviranjem motornih jedinica, porastom frekvencije pražnje-nja i sinhronizacijom mišićnih jedinica, omogu-ćuje stvaranje maksimalne mišićne sile. Trenažni sadržaji primjenjeni u ovom programu obuhvata-li su cjelokupni pokret, a ne samo silu pojedina-čnog mišića ili pokret u jednom izolovanom zglobu, što je rezultiralo boljom intermuskula-rnom $i$ intramuskularnom koordinacijom mišića.

Nisu registrovane statistički značajne promjena u pogledu vremena ostvarenja maksimalne sile (slika 3.). Uzrok tome leži u frekvenciji pražnjenja, odnosno učestalosti aktiviranja motornih jedinica. Brzina pražnjenja nervnih impulsa zavisi od više faktora, a CNS i broj brzih vlakana u mišiću, igraju ključnu ulogu. Budući da su to faktori koji su genetski određeni, na njih je teže uticati trenažnim procesom. Vjerovatno je potreban duži vremenski period primjene pliometrijskog treninga kako bi se pozitivno dijelo- 
valo na ove faktore, što može biti tema nekog narednog istraživanja.

I u testu Squat jump-a usljed primjene eksperimentalnog faktora, statistički značajno se poboljšala maksimalna visina skoka u eksperime-ntalnoj grupi $(p=.00)$, dok je to povećanje izo-stalo u kontrolnoj grupi $(p=.09)$ (slika 4.). Holcomb (1996) je testirajući pliometrijski prog-ram treninga na 51 studentu u periodu od osam nedjelja, dobio poboljšanje maksimalne visine skoka u Countermovement jump-u i Squat jump-u. Zabilježeno je i statistički značajno povećanje maksimalne sile (slika 5), međutim, interesantno je da se povećanje dogodilo u obe testirane grupe. Dok je u eksperimentalnoj grupi to bilo i očekivano, u kontrolnoj grupi je ova promjena bila iznenađujuća. Teško je napredak kontrolne grupe pripisati bilo kojem logičnom fiziološkom ili miogenom adaptivnom procesu. Kao najvjerovatnije dva uzroka napretka kontro-Ine grupe koja nije bila sistematski trenirana u pogledu razvoja sile moguće je navesti ili nedosljednost u kontroli ugla između nadkoljenice $i$ potkoljenice zauzetog prije izvođenja skoka (ugla od $90^{\circ}$ ) ili veću motivaciju ispitanika kontrolne grupe na finalnom mjerenju. Slične podatke, na uzorku od petnaest dječaka u periodu od deset nedjelja Kotzamanidis (2006) je dobio testirajući maksimalnu visinu skoka pri izvođenju Squat jump-a. Što se stiče vremena ostvarenja maksimalne sile (slika 6.), zavisna od brzine ekscitacije motornih jedinica, statistički značajnih promjena nije bilo u testiranim grupama.

\section{ZAKLJUČAK}

$U$ periodu od deset nedjelja ispitivan je uticaj pliometrijskog treninga na eksplozivnu snagu opruzača nogu. Uspoređivanjem rezultata sa inicijalnog i finalnog mjerenja dobijeni su rezultati na osnovu kojih su doneseni sljedeći zaključci:

- Pliometrijski trening trening je uticao na poboljšanje maksimalne visine skoka, maksimalne sile u koncentričnoj kontrakciji tokom izvođenja Countermovement jump-a i Squat jump-a. Nameće se zaključak da izvođenjem dinamičkih kretnji tipa skokova proizvešće se akutno poboljšanje u manifestaciji ekslozivne sile. Primjenjeni program nije statistički značajno uticao na vrijeme ostvarenja maksimalne sile.

- U kontrolnoj grupi nisu utvrđene signifikantne promjene nakon eksperimentalnog tretmana osim u varijabli maksimalna sila kod testa (Squat jump. Ovakvi rezuItati su sasvim očekivani budući da ispitanici kontrolne grupe nisu bili podvrgnuti dodatnim treninzima snage. Izuzetak u pogledu maksimalne sile može se smatrati slučajnim, jer od ukupno devet testiranih varijabli u testovima skočnosti, samo u jednoj je zabilježeno statistički značajno poboljšanje.

\section{LITERATURA:}

[1] Adams, K., O'Shea, JP., O'Shea, KL., Climstein, M. (1992). The effect of six weeks of squat, plyometric and squat-plyometric training on power production. The Journal of Applied Sport Science Research, 6(1), pp.36-41.

[2] Bosco, C., Ito, A., Komi, P V., Luhtanen, P., Rahkila, P., Rusco, H., Viitasalo, J T. (1982). Neuromuscular function and mechanical efficiency of human leg extensor muscles during jumping exercises. Acta physiologica scandinavica, 114(4), pp.543-550.

[3] Fatouros, IG., Jamurtas, AZ., Leontsini, D., Taxildaris, K., Aggelousis, N., Kostopoulos, N., Buckenmeyer, P. (2000). Evaluation of plyometric exercise training, weight training, and their combination on vertical jumping performance and leg strength. The Journal of Strength \& Conditioning Research, 14(4), pp.470-476.

[4] Holcomb, WR., Lander, JE., Rutland, RM., Rodney, M., Wilson, GD. (1996). The effectiveness of a modified plyometric program on power and the vertical jump. The Journal of Strength \& Conditioning Research, 10(2), pp.89-92. 
[5] Matavulj, D., Kukolj, M., Ugarkovic, D., Tihanyi, J., Jaric, S. (2001). Effects of plyometric training on jumping performance in junior basketball players. Journal of Sports Medicine and Physical Fitness, 41(2), pp. 159-164.

[6] Komi, P. (2000). Stretch-shortening cycle: a powerful model to study normal and fatigued muscle. Journal of Biomechanics, 33(10), pp.1197-1206.

[7] Kotzamanidis, C. (2006). Effect of plyometric training on running performance and vertical jumping in prepubertal boys. The Journal of Strength \& Conditioning Research, 20(2), pp.441-445.

[8] Kyrolainen, H., Avela, J., McBride, JM., Koskinen, S., Andersen, JL., Sipila, S., Takala, TE., Komi, PV. (2004). Effects of power training on mechanical efficiency in jumping. European Journal of Applied Physiology, 91(2-3), pp.155-159.

[9] Kyrolainen, H., Avela, J., McBride, JM., Koskinen, S., Andersen, JL., Sipila, S., Takala, TE., Komi, PV. (2005). Effects of power training on muscle structure and neuromuscular performance. Scandinavian Journal of Medicine \& Science In Sports, 15(1), pp.58-64.

[10] Luebbers, PE., Potteiger, JA., Hulver, MW., Thyfault, JP., Carper, MJ., Locwood, RH. (2003). Effects of plyometric training and recovery on vertical jump performance and anaerobic power. The Journal of Strength \& Conditioning Research, 17(4), pp.704-709.

[12] Potach, D H., Katsavelis, D., Karst, GM., Latin, RW., Stergiou, N. (2009). The effects of a plyometric training program on the latency time of the quadriceps femoris and gastrocnemius short-latency responses. The Journal of Sports Medicine and Physical Fitness, 49(1), pp.35-43.

[13] Potteiger, JA., Lockwood, RH., Haub, MD., Dolezal, BA., Almuzaini, KS., Schroeder, JM., Zebas, CJ. (1999). Muscle power and fiber characteristics following 8 weeks of plyometric training. The Journal of Strength \& Conditioning Research, 13(3), pp.275-279.

Rad primljen: 16.06.2010. godine Rad odobren: 12.07.2010. godine

Adresa za korespodenciju: mr Aleksandar Kukrić, Fakultet fizičkog vaspitanja i sporta Bul. Vojvode Petra Bojovića 1A 78000 Banjaluka, BiH Tel. +38765415239 e-mail: a.kukric@yahoo.com 